Document downloaded from:

http://hdl.handle.net/10251/94464

This paper must be cited as:

Mesejo Conejos, C.; Reig Valor, C.; Martinez Fuentes, A.; Gambetta, G.; Gravina Telechea, A.; Agustí Fonfría, M. (2016). Tree water status influences fruit splitting in Citrus. Scientia Horticulturae. 209:96-104. doi:10.1016/j.scienta.2016.06.009

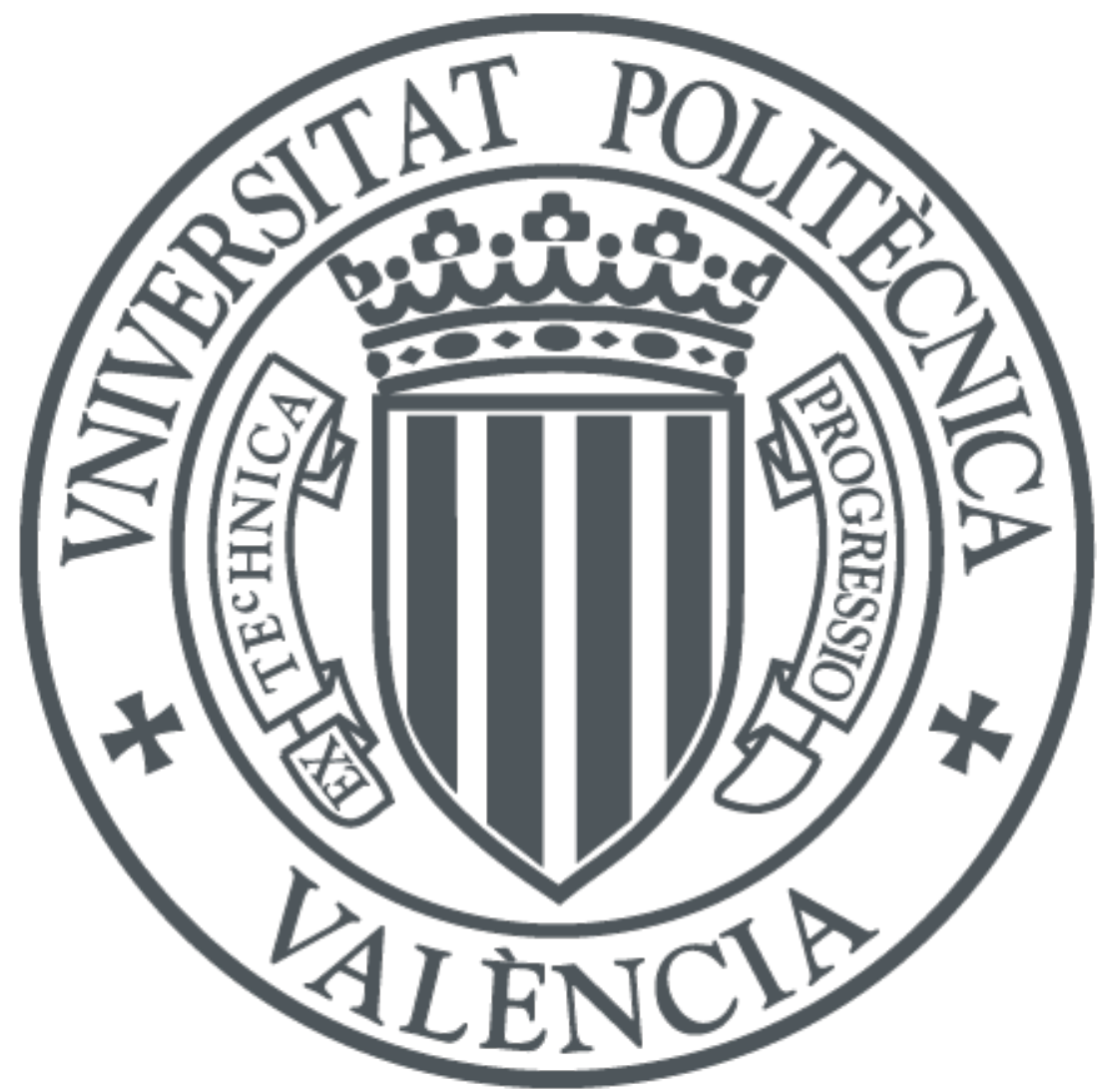

The final publication is available at

https://doi.org/10.1016/j.scienta.2016.06.009

Copyright Elsevier

Additional Information 


\section{Tree water status influences fruit splitting in Citrus}

2

3 Carlos Mesejo $^{1}$, Carmina Reig ${ }^{1}$, Amparo Martínez-Fuentes ${ }^{1}$, Giuliana Gambetta ${ }^{2}$,

$4 \quad$ Alfredo Gravina², Manuel Agustí ${ }^{1 *}$

$5 \quad{ }^{1}$ Instituto Agroforestal Mediterráneo, Universitat Politècnica de València, Camino de

6 Vera s/n, 46022, València, Spain

7 e-mails: $\quad$ carmeco@upv.es, $\quad$ mareiva@prv.upv.es; $\quad$ demarfue@upvnet.upv.es,

8 magusti@prv.upv.es

$9 \quad{ }^{2}$ Facultad de Agronomía, Universidad de La República, Avenida Garzón 780, 12900,

10 Montevideo, Uruguay

11 e-mails: gambetta@fagro.edu.uy, agravina@fagro.edu.uy

12

13 *corresponding author: magusti@prv.upv.es

14

15

16

17

18

19

20

21

22

23

24

25 


\section{Abstract}

29 Fruit splitting or cracking is a major physiological disorder in fruit trees markedly 30 influenced by environmental conditions, but conclusive data still are required to provide 31 a definite explanation and preventive measures. Changes in climatic conditions 32 critically influence fruit splitting incidence. We studied plant-soil-ambient water relations in splitting-prone citrus grown under 4 contrasting environmental conditions

34 (climate type and soil), in Spain and Uruguay, over a six years period. Automatic trunk and fruit diameter measurements (trunk and fruit growth rate and maximum daily trunk shrinkage), which indicate tree water status, together with factors modifying the tree and fruit water relationship (temperature, ET, rainfall, soil texture, soil moisture, rootstock and xylem anatomy) were studied and correlated with splitting.

A close fruit splitting and soil texture relationship was found, inversely correlated with clay and silt percentages, and positively with those for sand. Under 85\%-sand soil conditions, slight changes in soil moisture due to fluctuations in temperature, ET, or rainfall changed trunk and fruit growth rate patterns during few hours and induced splitting. Splitting incidence was higher in trees with larger xylem vessels in the fruit peduncle due to rootstock ('Carrizo' and 'C-35' citrange being higher than 'FA-5', 'Cleopatra' and P. trifoliata). Finally, reducing the frequency of irrigation by half increased midday canopy temperatures $\left(\sim 5^{\circ} \mathrm{C}\right)$ and splitting $(+15 \%)$. We conclude that irregularities in the tree water status, due to interactions among soil moisture, rootstock and climatic conditions, leads to a number of substantial changes in fruit growth rate increasing the incidence of fruit splitting. 
51 Key words

52

53 Citrus, Climate, Physiological disorder, Splitting, Trunk growth rate, Soil

54

55

56

57

58

59

60

61

62

63

64

65

66

67

68

69

70

71

72

73

74

75 
77

78

\section{Introduction}

Physiological disorders in fruit trees are mainly caused by environmental factors such as climate or soil quality. Changes in the absorption and loss of water can cause most of them (Agustí et al., 2004). Splitting (or cracking) is a major pre-harvest physiological disorder in fruit tree species including pome fruits (Kasai et al., 2008), stone fruits (Sekse, 1995), grapes (Clarke et al., 2010), figs (Kong et al., 2013), litchi (Huang et al., 2008), and citrus (Almela et al., 1994). Among the latter, 'Navel' and 'Valencia' sweet oranges (Citrus sinensis) are prone to split (Bar-Akiva, 1975; De Cicco et al., 1988), as are some Clementine mandarins (Citrus clementina) (Cronjé et al., 2013), and, specially, mandarin hybrids 'Nova', 'Murcott' and 'Ellendale' (Almela et al., 1994; Barry and Bower, 1997; García-Luis et al., 2001).

Citrus fruit consists of 8-16 clustered carpels that form locules in which juice sacs grow developing the pulp. Ovary walls form fruit rind, which is made up of the spongy internal layer, the albedo (mesocarp), and the external compact layer, the flavedo (exocarp). In citrus, splitting is a consequence of disruption between pulp and rind growth. During the cell enlargement stage the increase in fruit volume is mainly due to pulp growth, and rind thickness progressively diminishes. Although the mesocarp may temporarily alleviate pulp pressure because of its sponginess, the exocarp is more rigid and will eventually crack (Kaufman, 1970). Pressure applied by the rapidly expanding pulp during fruit growth leads to the formation of microcracks in the flavedo and initiation of fruit split (Cronjé et al., 2013).

Fruit splitting has been associated with anatomical, physiological and environmental factors, and their interactions. In citrus, anatomical factors increasing fruit splitting are related to the presence of an open stylar end in the ovary (García-Luis et al., 2001, 
101 1994) or an oblate fruit shape (García-Luis et al., 2001), whereas peel thickness is 102 negatively related to splitting (Almela et al., 1994). It was suggested that splitting 103 occurs when a sudden net influx of water and solutes into the fruit coincides with other 104 factors reducing skin elasticity and strength (Peet, 1992). In apple, the expression in the 105 pulp of expansin MdEXPA3, which regulates cell wall extensibility and induces cell 106 expansion, exceeds that in the peel during the cracking period (Kasai et al., 2008). 107 Additionally, low calcium concentrations (soluble, structural or oxalate) in the pericarp 108 and drought conditions, which reduce calcium uptake, also contribute to fruit cracking 109 (Huang et al., 2008).

110 Fruits on the same tree, individually considered, differ in their response to splitting, 111 indicating that endogenous factors play a crucial role in the incidence of the disorder. 112 By contrast, splitting varies considerably between years and orchards, suggesting a 113 relevant relationship with environmental factors (Almela et al., 1994). Environmental 114 factors associated with fruit splitting include soil moisture, rainfall, relative humidity, 115 temperature and exposure to sunlight (Opara et al., 1997). It is generally assumed that 116 splitting is a result of a sudden increase in the water content of the soil, atmospheric 117 humidity, or temperature (Opara et al., 1997), but conclusive data are still needed in 118 order to obtain a definite explanation. For instance, seasonal water deficit followed by 119 rain during the cell enlargement stage has been linked to splitting in 'Nova' mandarin 120 grown in dry hot summers in the Mediterranean basin (Valencia, Spain) (Almela et al., 121 1990), but not when grown in temperate climate with humid hot summers (Uruguay) 122 (Gravina, unpublished results). Likewise, rainfall did not correlate significantly with 123 splitting in 'Ellendale' mandarin grown in hot humid areas (South Africa) (Rabe and 124 Van Rensburg, 1996). 
125 These observations indicate that splitting is a highly complex disorder, which cannot

126 be attributed to one single factor. In this research we tested the hypothesis that variable

127 tree water status induce sudden stressful changes in fruit growth patterns which in turn

128 lead to splitting. We studied plant-soil-ambient water relations in splitting-prone citrus

129 grown under 4 contrasting environmental conditions in Spain and Uruguay over a six 130 years period.

131

132

2. Materials and methods

133

134 2.1. Experimental design, plant material and orchard characteristics

135

136 Four experiments were conducted: 1) study of the relationship between environmental

137 (climate type and soil) conditions and fruit splitting; 2) study of the relationship

138 between tree water status and fruit splitting; 3) study of the relationship between xylem

139 anatomy and fruit splitting; 4) study of effect of the irrigation frequency on fruit 140 splitting.

141 The first experiment was conducted over a 6 years period (2009-2012; 2014-2015;

142 Table 1) with 10- to 14-year-old 'Nova' mandarin trees [Citrus clementina $\mathrm{x}$ tangelo

143 'Orlando' (Citrus.reticulata x Citrus. paradisi)], grown in five orchards under

144 contrasting environmental conditions. Three of the five orchards were in Spain, two in

145 Valencia ( $\left.39^{\circ} 35^{\prime} \mathrm{N}, 0^{\circ} 44^{\prime} \mathrm{W}\right)$, in the Mediterranean coast, and one in Huelva $\left(37^{\circ} 25^{\prime} \mathrm{N}\right.$,

$\left.1467^{\circ} 3^{\prime} \mathrm{W}\right)$ in the Atlantic coast. Two more orchards were located in Uruguay, one in

147 Libertad ( $34^{\circ} 40^{\prime}$ S, $56^{\circ} 42^{\prime} \mathrm{W}$ ), in the Rio de la Plata coast, and the other in Salto ( $31^{\circ}$

$14824^{\prime} \mathrm{S}, 57^{\circ} 50^{\prime} \mathrm{W}$ ), a continental plot. Fruit splitting was measured in 10 trees per orchard

149 every 15 days during 4 months (end of summer to early fall) in each of the 6 years 
150 studied. Different trees were selected each year according to their uniformity in size and

151 fruit yield. Split fruits were counted and removed from the tree. Dropped split fruits 152 were also counted and removed from below the tree. At harvest, the number of fruits 153 remaining on the tree was recorded. A climatic station (Verdtech Nuevo Campo S.A., 154 Madrid, Spain) automatically recorded temperature, rainfall, evapotranspiration, and 155 soil moisture (see below).

156 Orchards were selected to obtain a range of soil and climatic conditions. Soils were 157 classified according to soil texture (USDA; www.nrcs.usda.gob) and soil characteristics 158 were determined by AGQ Labs and Technological Services S.A (Spain) (for more 159 details visit www.agq.com.es). In Spain, the Valencia orchards had loamy (48\% sand, $16016 \%$ clay, $36 \%$ silt) to sandy-loam $(72 \%, 14 \%, 14 \%)$ soil texture, $\mathrm{pH}$ 7.2-7.5, and 2.5$1613.5 \%$ organic matter. The Huelva orchards had sandy-loam (76\%, 10\%, 14\%) to loamy162 sand $(85 \%, 10 \%, 5 \%)$ soil texture, $\mathrm{pH}$ 7.3-7.6 and $0.3-0.5 \%$ organic matter. In 163 Uruguay, the Libertad orchard had silty-clay-loam (16\%, 32\%, 52\%) texture, pH 7.1 164 and $2.9 \%$ organic matter, whereas the Salto orchard had fine-sand (94\%, 4\%, 2\%) 165 texture, and $0.5 \%$ organic matter. Thus, the orchards differed mainly in terms of soil 166 texture and organic matter content. According to the Köppen-Geiger climatic 167 classification (Peel et al., 2007), Valencia and Huelva (in Spain) are Csa climate-type 168 (temperate, dry summer, hot summer), whereas Libertad and Salto (in Uruguay) are Cfa 169 climate-type (temperate, without dry season, hot summer) . Therefore, the main climatic 170 difference in the selected orchards is rainfall during summer, coinciding with the fruit 171 enlargement stage. Average rainfall is $350 \mathrm{~mm}$ year ${ }^{-1}$ in Valencia, $750 \mathrm{~mm}$ year $^{-1}$ in 172 Huelva and $1200 \mathrm{~mm}$ year $^{-1}$ in Libertad and Salto. In Spain, 'Nova' trees were grafted 173 onto Carrizo citrange (Citrus sinensis x Poncirus trifoliata) and Forner-Alcaide-5 174 (Poncirus trifoliata x Citrus reshni) rootstocks, and onto Poncirus trifoliata in Uruguay. 
175 Fertilization, drip irrigation, pruning and pest management were in accordance with

176 optimum commercial practice. Irrigation was applied in order to refill the estimated 177 crop evapotranspiration during the entire season.

178 The second experiment was carried out with 12-year-old (at the onset of the 179 experiment) 'Nova' mandarin trees grafted onto Carrizo citrange rootstock planted in 180 Huelva (orchard Huelva I). The experiment was conducted during six years but only the 181 results for those with higher and lower incidence of fruit splitting (2010 and 2012; see 182 Table 1) are presented. Trunk and fruit diameter variation was automatically measured 183 in three representatives 'Nova' mandarin trees. Each tree was equipped with a radial 184 stem dendrometer (Plantsens, Verdtech Nuevo Campo SA, Madrid, Spain), placed 185 about $50 \mathrm{~cm}$ from the ground, and a fruit dendrometer (Plantsens, Verdtech Nuevo 186 Campo SA, Madrid, Spain) placed at an average fruit. Measurements were 187 automatically recorded (see below). Fruit splitting and climatic conditions were 188 recorded as previously explained.

189 In the third experiment, conducted during two years (2011-2012) in Valencia and 190 Huelva (Spain), three splitting-prone varieties and five rootstocks were used: 12-year191 old 'Nova' mandarin trees grafted onto Carrizo citrange and Forner-Alcaide-5 192 rootstocks (orchard Huelva I); 10-year-old 'Clemenrubi' clementine mandarin (Citrus 193 clementina) trees grafted onto Carrizo citrange and Poncirus trifoliata rootstocks 194 (orchard Huelva II); and 10-year-old 'Chislett' navel orange (Citrus sinensis) trees 195 grafted onto Carrizo citrange, C-35 citrange, Forner-Alcaide-5 and 'Cleopatra' 196 mandarin (Citrus reshni) (orchard Valencia III). Fruit splitting was measured as 197 previously explained in 10 trees per cultivar and rootstock combinations, and samples of 1985 fruits per tree and rootstock combinations were taken to determine peduncle vascular 199 tissue characteristics (see below). 
200 Finally, in the fourth experiment, the effect of irrigation frequency on fruit splitting 201 rate was studied in 12-year-old 'Nova' mandarin trees grafted onto Carrizo citrange 202 rootstock (orchard Valencia II, sandy-loam texture). Two irrigation treatments were 203 applied during September 2014: (1) to refill daily estimated crop ET (control treatment), 204 and (2) the same weekly water volume applied every other day. At the end of the 205 experiment, the control trees received $210 \mathrm{ltree}^{-1}$ week, $30 \mathrm{l}$ tree $^{-1} \mathrm{~d}^{-1}$ every day, 206 whereas the treated trees received $200 \mathrm{l}$ tree ${ }^{-1}$ week, $50 \mathrm{l}$ tree $\mathrm{e}^{-1} \mathrm{~d}^{-1}$ every other day. Tree 207 water status was indirectly measured by thermography. Canopy temperature (Tc) was 208 measured as indicated in Ballester et al., (2013) (see below).

\subsection{Environmental measurements}

212 Trunk diameter variations were determined by dendrometry in the experiments 213 conducted in Spain. The dendrometers were calibrated individually with a precision 214 micrometer (Verdtech Nuevo Campo SA, Madrid, Spain). The resolution of trunk and 215 fruit diameter measurements was $\pm 5 \mu \mathrm{m}$. Trunk diameter variations were used to 216 calculate the Trunk Growth Rate (TGR) and Maximum Daily Shrinkage (MDS) by the 217 difference between the maximum diameter, reached early in the morning, and the 218 minimum diameter, reached during the afternoon. Trunk diameter variations are also a 219 plant water status indicator (Goldhamer and Fereres, 2001).

220 Soil moisture was determined at $0.1,0.3$ and $0.6 \mathrm{~m}$ depth using C-Probe sensors 221 (AquaSpy, Inc., USA); Rain-O-Matic tipping bucket gauges (Pronamic Co. Ltd., 222 Sikeborg, Denmark) recorded precipitation; one combined sensor recorded air 223 temperature and relative humidity (Vaisalya Oyj, Helsinki, Finland). All sensor data 224 were automatically recorded every 30 s using an addWAVE A733GSM remote 
225 telemetry unit (Adcon Telemetry, Austria) for data storage and transmission, 226 programmed to report mean values every $15 \mathrm{~min}$.

227 In the experiments conducted in Uruguay, a digital tipping bucket rain gauge, with a 228 sensitivity of 1 tip per 0.2 mm (MD523, Pessl Instruments GES.M.B.H., Austria), 229 switched to a reed contact magnetically operated was used. In both locations, every 15 230 days, three soil samples of $0.5 \mathrm{~kg}$ were taken at 0-0.2 $\mathrm{m}$ and 0.2-0.4 $\mathrm{m}$ depth; they were 231 dried at $105{ }^{\circ} \mathrm{C}$ during $48 \mathrm{~h}$, and weighted. Soil moisture was determined as the 232 difference between wet and dry weigh.

233 Canopy temperature (Tc) was measured by taking frontal images, from a distance of $2341.5 \mathrm{~m}$, on the SW side of the tree at $10.30 \mathrm{~h}, 12.30 \mathrm{~h}$ and $14.30 \mathrm{~h}$ on a sunny day. 235 Measurements were taken with an infrared thermal camera TH9100 WR (NEC Avio 236 Infrared Technologies Co., Ltd., Tokio, Japan). Tc is indirectly related to the tree water 237 status in citrus (Ballester et al., 2013).

238

\subsection{Histological study}

241 Ten cross-sections of average size peduncles from 10 fruits of each scion-rootstock 242 combination were taken for histological analysis. Sections were fixed in FPA (10\% 243 formaldehyde, $10 \%$ propionic acid, $80 \%$ ethanol at $70 \%$ ). Cross-sections of $10 \mu \mathrm{m}$ 244 thickness were prepared $5 \mathrm{~mm}$ from the calyx with a microtome (Microm HM400R). 245 Preparations were stained in methylene blue for $5 \mathrm{~min}$. The total cross-sectional area of 246 secondary xylem, secondary phloem, cortex and pith were measured together with 247 radial number and diameter of major secondary xylem vessels and secondary phloem 248 cells. Each peduncle section was examined in three replicates. The number of xylem 249 vessels was calculated by multiplying the average number of vessels from 15 xylem 
250 rays by the total number of rays per cross-section. Thirty xylem vessels per cross251 section, randomly selected, were used to measure the average diameter. Average 252 phloem cell diameter was calculated by counting the number of cells in a given radial 253 length (75 $\mu \mathrm{m})$. A Nikon E600 (Japan) light microscope was used for measurements.

\subsection{Statistical analysis}

Analysis of variance and regression analysis were performed on the data, using the Student-Newman-Keuls’ multiple range test for means separation. Percentages were analysed after arc sin transformation.

\section{Results}

\subsection{Environmental conditions and splitting incidence}

265 The incidence of fruit splitting depended on the orchard and the year. For a given year 266 (2012), the splitting percentage in the 'Nova' mandarin varied among orchards from Valencia III, the splitting percentage varied among years from $8.7 \%$, $8 \%$ and $5 \%$ to 27.0\%, 16\% and14\%, respectively (Table 1). Nevertheless, in some cases, no significant

270 differences among years were found for a given orchard. For instance, the splitting 271 incidence in the Libertad orchard was always the same $(<2 \%)$ (Table 1$)$.

272 Hence, results suggest a close relationship between environmental factors and splitting. 273 Accordingly, the influence of soil texture, soil moisture (SM \%), and climatic 274 conditions [average temperature, $\mathrm{t}_{\mathrm{m}}\left({ }^{\circ} \mathrm{C}\right)$; evapotranspiration, $\mathrm{ET}_{0}\left(\mathrm{~mm} \mathrm{~d}^{-1}\right)$; and 
275 precipitation, $\mathrm{P}(\mathrm{mm})$ ] on the incidence of fruit splitting was studied. Soil texture 276 significantly varied between orchards and, thus, in 'Nova' mandarin splitting correlated 277 inversely with clay and silt percentages, and positively with sand percentages $(P<0.05$; 278 Figure 1).

279 Under 85\% sand soil conditions (Huelva I orchard, Spain), the highest yearly rate of 280 incidence of split fruit coincided in dates (late September) but not in intensity. Both 281 total splitting incidence and number of fruits split per tree and day were significantly 282 higher in 2010, 27\% and 4.8 split fruits tree $\mathrm{d}^{-1}$ on average, respectively, than in 2012, $2838 \%$ and 1.2 split fruits tree $\mathrm{e}^{-1} \mathrm{~d}^{-1}$, on average, respectively (Figure 2A and 2B). Fruit 284 splitting started at the same phenological fruit growth stage (70\% fruit size) in both 285 years and in both the Huelva (Figure 2A and 2B) and Uruguay orchards (data not 286 shown).

287 Regarding climatic conditions at this critical period (September), no significant 288 differences were found in the time-course or the average $t_{m}, \mathrm{ET}_{0}$ and $\mathrm{P}$ between 289 September 2010 and September 2012 in the Huelva I orchard (Figure 2C-2H). In both 290 years, $\mathrm{t}_{\mathrm{m}}$ and $\mathrm{ET}_{0}$ diminished progressively over time. Average $\mathrm{t}_{\mathrm{m}}$ was $22.7^{\circ} \mathrm{C}$ and $29122.5^{\circ} \mathrm{C}$, and average $\mathrm{ET}_{0}$ was $4.1 \mathrm{~mm} \mathrm{~d}^{-1}$ and $3.9 \mathrm{~mm} \mathrm{~d}^{-1}$, in September 2010 and 292 September 2012 respectively. The average rainfall was $0.32 \mathrm{~mm} \mathrm{~d}^{-1}$ and 0,31 $\mathrm{mm} \mathrm{d}^{-1}$ in 293 September 2010 and September 2012, respectively. It rained only on two days in 2010 294 (5.6 and $3.8 \mathrm{~mm} \mathrm{~d}^{-1}$ ) and on 3 days in 2012 (1.6, 5.2, $1.6 \mathrm{~mm} \mathrm{~d}^{-1}$ ) (Figure 2G and 2H). 295 However, SM significantly differed between years in the Huelva I orchard. In 2010, 296 average SM (8.3\%) and minimum SM (7.4\%) were significantly lower than in 2012 297 (9.1\% and 8.6\%, respectively). But more importantly, average daily SM progressively 298 fell in 2010 but was remained almost constant in 2012. A detailed study of the average daily SM at 10, 30 and $60 \mathrm{~cm}$ depth also revealed significant differences between years 
300 (Figure 2I and 2J). In 2010, average daily SM at $10 \mathrm{~cm}$ depth exhibited frequent sharp 301 changes reaching up to a 20\% variation, whereas in 2012 changes hardly reached 5\% until mid-October, afterwards with changes similar to 2010. Values for daily average $\mathrm{SM}$ at 30 and $60 \mathrm{~cm}$ depth also varied significantly between years, those for 2010 steadily decreasing until mid-October and increasing afterwards, and those for 2012 varying continuously during the period of the study.

306 In order to determine the contribution of the climatic factors to the splitting incidence, under 85\%-sand soil conditions (Huelva I orchard), a multiple regression analysis was performed including 6 quantitative variables (every $15 d$ recording changes in $\mathrm{t}_{\mathrm{m}}, \mathrm{ET}_{0}, \mathrm{P}$, $\mathrm{SM}_{10}, \mathrm{SM}_{30}$, and $\mathrm{SM}_{60}$ ) and the year as a qualitative variable. Only $\mathrm{SM}_{60}$ and year 310 variables were found to be statistically significant $[P<0.01$; Splitting $(\%)=23,0+$ 311 178,1·SM $60-46,9 \cdot$ Year]. This result is reinforced by the relationship between soil moisture and fruit splitting in the two Uruguay orchards in 2015 (Figure 3). During the splitting period (February-April, SH), the orchard located in Libertad (1\% fruit splitting,

314 16\% sand) had a significantly higher SM than the orchard located in Salto (7.5\% fruit 315 splitting, 94\% sand). But more importantly, in Salto, SM was irregular varying from $31610 \%$ to $37 \%$ whereas in Libertad SM varied less (0.7-fold in average) from 53\% to 41\%. Under these conditions, rainfall was only correlated to fruit splitting in Salto (data not shown). These results suggest a relationship between tree-water status and splitting incidence.

\subsection{Tree water status and splitting incidence}

323 TGR, as a tree water status indicator, and FGR were found to be closely correlated for a 324 given tree. In general, both trunk and fruit diameter increased from 5 pm until 9 am (16 
$325 \mathrm{~h} \mathrm{~d}^{-1}$ ) the fruit increasing at a rate of $45 \mu \mathrm{m} \mathrm{h}^{-1}$; on the contrary, both TGR and FGR 326 decreased from 9 am to $5 \mathrm{pm}\left(8 \mathrm{~h} \mathrm{~d}^{-1}\right)$ and fruit decreased at a rate of $72 \mu \mathrm{m} \mathrm{h}^{-1}$.

327 Notwithstanding, this trend varied depending on climatic conditions that temporarily 328 induced notable changes in FGR, TGR and MDS (Figure 4). For instance, on September $32916^{\text {th }}$ and $17^{\text {th }}$ (2010) two important events were observed (Figure 4A): 1) TGR was 330 significantly less $(-7.5 \%)$ at mid-day on September $16^{\text {th }}$; then, a sudden increase $331(+11 \%)$ in TGR occurred at $4 \mathrm{pm}$ (it rained $3.8 \mathrm{~mm}$ ) and continued until 10 am on $17^{\text {th }}$; 332 2) on the $17^{\text {th }}$ the trunk did not shrink. As a result, fruit changed its natural daily 333 growing pattern (16 h increase, $8 \mathrm{~h}$ decrease) and grew continuously at maximum 334 growth rate (55.9 $\mu \mathrm{m} \mathrm{h}^{-1}$ on average) for $46 \mathrm{~h}$. Under these conditions, the fruit splitting 335 rate rose from 6 to 10 split fruits a day.

336 Changes in TGR and MDS were found to be more intense and much more frequent in 3372010 (Figure 4B and 4C) than in 2012 (Figure 4D and 4E), and splitting incidence was significantly higher in the former (Table 1). More importantly, they coincided with pronounced changes in the fruit splitting rate and in $\mathrm{t}_{\mathrm{m}}, \mathrm{ET}_{0}$ and $\mathrm{P}$ (Figure 2).

340 In Citrus, tree water status has been related with the xylem vessels diameter which, in 341 turn, is influenced by rootstock. Thus, it was logical studying the effect of the rootstock 342 on the splitting incidence. The histological study of the peduncles showed that the 343 number of xylem vessels per peduncle did not differ significantly among rootstocks 344 (data not shown), but the average diameter of xylem vessel in peduncles was $8 \%$ to $15 \%$ 345 larger in the citrange rootstocks than in the Cleopatra mandarin, FA-5, and P. trifoliata 346 (Figure 5B). Indeed, the average proportion of affected fruit in trees grafted onto 347 citrange rootstocks, Carrizo and C-35, varied between $9 \%$ and $16 \%$ on average, 348 depending on the species ('Nova' mandarin > 'Clemenrubi' Clementine mandarin > 349 'Chislett' Navel orange), and was significantly higher than in trees grafted onto 
350 Cleopatra mandarin, FA-5 and P. trifoliata rootstocks (Figure 5A), and it paralleled the 351 percentage of split fruit.

352 Accordingly, reducing the frequency of irrigation by half in September, without 353 reducing the total amount of water, significantly modified the tree water status under 354 sandy-loam soil conditions, and increased fruit splitting. Higher midday canopy 355 temperatures $\left(\sim 5^{\circ} \mathrm{C}\right)$ and higher rates of fruit splitting were found for trees in these 356 conditions, with the average final splitting incidence being $19 \%$ compared to $8 \%$ in 357 daily irrigated trees (Figure 6). Fruit from trees irrigated every other day had larger and 358 more micro-cracks at the stylar end compared to fruit from those irrigated every day 359 (data not shown).

\section{Discussion}

363 Fruit splitting is defined as an extreme form of fruit cracking in which the skin cracks 364 progressively due to pulp pressure (Cronjé et al., 2013; Opara et al., 1997). In pome and 365 stone fruits cracking is easily distinguishable because of their thin skin (Kasai et al., 366 2008). However, this is not the case in citrus. Nevertheless, the mechanism by which external factors influence fruit splitting seems to be the same regardless of the species: unstable tree water status induces acute changes in the fruit growth pattern which leads to splitting. Our results support this hypothesis since 1) fruit splitting correlates 370 positively to the percentage of sand in the soil, and inversely to that of clay and silt; 2) 371 under sandy-soil conditions slight variations in soil moisture significantly increase 372 splitting incidence; 3) reducing irrigation frequency increases splitting incidence; 4) 373 rootstocks developing larger xylem vessels in fruit peduncle significantly increase 374 splitting incidence regardless of soil conditions or species; 5) sharp changes in TGR and 
375 MDS parallel changes in fruit growth rate, and 6) the greater TGR and MDS variation, 376 the higher splitting incidence.

377 As a rule, fruit increases in weight during the night-time and early morning whereas it does not increase and even decreases during daytime, when transpiration reaches its maximum (Fishman and Génard, 1998). As turgor pressure drives cell expansion, its

380 diurnal variation in the fruit correlates with fruit fresh mass, showing a sharp decline in 381 the morning and a marked rise in the evening (Fishman and Génard, 1998). However, 382 this is not always observed in natural conditions. In our experiments, fruit from tree growing in extreme sandy-soil conditions (Huelva, Spain) showed significant changes in this pattern (see Fig. 5A), which is due to their high sensibility to tree-water-status variations. Thus, at the end of summer, a single $5 \mathrm{~mm}$ rain-day was able to induce continuous fruit growth for more than 40 h (Figs. 3 and 5), resulting in a pulp hydrostatic pressure that might exceed the rind ability to sustain it, causing fruit to split. The increase in splitting took place thereafter. Nevertheless, $100 \mathrm{~mm}$ rain in the same period did not induce splitting in fruit from tree growing in silty-clay soil conditions in Libertad, Uruguay (Fig. 4). In apple, splitting mainly occurs while expansins expression (MdEXPA3) is lower in the peel than in the pulp (Kasai et al., 2008).

We found a relevant correlation between the degree of MDS and the percentage of split fruit $(\mathrm{y}=7.5867 \mathrm{x}-2.8145 ; \mathrm{r}=-0.9046 ; \mathrm{P}<0.05)$ during the rapid fruit growth period (until $80 \%$ fruit volume was achieved) but not later. This is because xylem flow positively correlates with stem-to-fruit pressure potential gradient during the initial, but not the final part of the developing period, when xylem conductivity appears to be reduced (Morandi et al., 2010). Shrinkage is caused by xylem back flow (Davies et al., 2000). Accordingly, we found a significant correlation due to rootstock differences between xylem vessel area in the fruit peduncle and fruit splitting. Fruits from trees 
400 grafted onto citranges 'Carrizo' and 'C-35' rootstocks had larger xylem vessels and a 401 higher incidence of splitting regardless of soil conditions or species. Larger xylem 402 vessels appeared to be related to higher hydraulic conductance in roots which gives rise 403 to different mass flows of water to the canopy, strongly influencing tree water 404 relationships (Rodríguez-Gamir et al., 2010). Therefore, the larger the xylem vessels the 405 greater the instability in the tree-water status, giving rise to more pronounced daily fruit 406 shrinkage - expansion. Furthermore, fewer and smaller micro-cracks were found in the 407 stylar end of non-split fruit from regularly irrigated trees.

408 In our experiments, not every significant variation in daily TGR resulted in a 409 significant variation in fruit splitting rate (measured every $15 \mathrm{~d}$ ), and the largest TGR 410 variations (during summer) did not produce the greatest increase in fruit splitting rates. 411 The rind thickness time-course may provide a suitable explanation of this as it 412 progressively diminishes from the onset of linear fruit growth stage, early summer, 413 reaching minimum values when fruit stops growing in early autumn (Bain, 1958). 414 Accordingly, spongy mesocarp may alleviate pulp pressure better during the initial, 415 rather than the final, stage of fruit growth. The negative relationship between peel 416 thickness and splitting found in 'Nova' mandarin was previously reported (Almela et 417 al., 1994).

418 In conclusion, fluctuations in the tree water status due to the interaction between soil 419 moisture, rootstock and climatic conditions lead to sharp changes in the fruit growth 420 rate causing fruit splitting.

421

\section{Abbreviations}


$424 \mathrm{ET}_{0}$ : evapotranspiration; FGR: fruit growth rate; MDS: maximum daily trunk shrinkage;

425 P: precipitation; Tc: canopy temperature; TGR: trunk growth rate; tm: average 426 temperature; SM: soil moisture

427

\section{6. Acknowledgements}

429

430 Authors thank Agrimarba S. A. (Huelva, Spain), Cooperativa de Llíria (Valencia, 431 Spain), Frutícola Libertad (Libertad, Uruguay) and Citrícola Salteña (Salto, Uruguay) 432 for providing technical assistance and the orchards.

\section{References}

435

436

Agustí, M., Almela, V., Juan, M., Martinez-Fuentes, A., Mesejo, C., 2004. Quality of Citrus for Fresh Consumption as Affected by Water Relationships. Acta Hortic. 632, $141-148$.

Almela, V., Agust1, M., Aznar, M., 1990. El ‘splitting' o rajado del fruto de la mandarina Nova. Su control, in: Actas de Horticultura. pp. 142-147.

Almela, V., Zaragoza, S., Primo-Millo, E., Agustı, M., 1994. Hormonal control of splitting in 'Nova’ mandarin fruit. J. Hortic. Sci. 69, 969-973.

Bain, J.M., 1958. Morphological, anatomical, and physiological changes in the developing fruit of the Valencia orange, Citrus sinensis (L) Osbeck. Aust. J. Bot. 6,

446 Ballester, C., Jiménez-Bello, M.A., Castel, J.R., Intrigliolo, D.S., 2013. Usefulness of 447 thermography for plant water stress detection in citrus and persimmon trees. Agric. $448 \quad$ For. Meteorol. 168, 120-129. 
449 Bar-Akiva, A., 1975. Effect of potassium nutrition on fruit splitting in Valencia orange.

$450 \quad$ J. Hortic. Sci. 50, 85-89.

451 Barry, G.H., Bower, J.P., 1997. Manipulation of fruit set and stylar-end fruit split in

452 'Nova’ mandarin hybrid. Sci. Hortic. (Amsterdam). 70, 243-250.

453 doi:10.1016/S0304-4238(97)00025-3

454 Clarke, S.J., Hardie, W.J., Rogiers, S.Y., 2010. Changes in susceptibility of grape

455 berries to splitting are related to impaired osmotic water uptake associated with

456 losses in cell vitality. Aust. J. Grape Wine Res. 16, 469-476. doi:10.1111/j.1755-

$457 \quad 0238.2010 .00108 . x$

458 Cronjé, P.J.R., Stander, O.P.J., Theron, K.I., 2013. Fruit Splitting in Citrus. Hortic. Rev.

459 Vol. 41 177-200. doi:10.1002/9781118707418.ch04

460 Davies, W.J., Bacon, M.A., Thompson, D.S., Sobeih, W., González Rodríguez, L.,

4612000 . Regulation of leaf and fruit growth in plants growing in drying soil:

462 exploitation of the plants' chemical signalling system and hydraulic architecture to

463 increase the efficiency of water use in agriculture. J. Exp. Bot. 51, 1617-1626.

464 doi:10.1093/jexbot/51.350.1617

465 De Cicco, V., Intrigliolo, F., Ippolito, A., Vanadia, S., Giuffrida, A., 1988. Factors in

466 Navelina orange splitting, in: Proceedings of the International Society of

$467 \quad$ Citriculture. pp. 535-540.

468 Fishman, S., Génard, M., 1998. A biophysical model of fruit growth: Simulation of

469 seasonal and diurnal dynamics of mass. Plant, Cell Environ. 21, 739-752.

$470 \quad$ doi:10.1046/j.1365-3040.1998.00322.x

471 García-Luis, A.,. Duarte, a. M.M., Kanduser, M., Guardiola, J.L., 2001. The anatomy

472 of the fruit in relation to the propensity of citrus species to split. Sci. Hortic.

473 (Amsterdam). 87, 33-52. doi:10.1016/S0304-4238(00)00158-8 
474 García-Luis, A., Duarte, a. M.M., Porras, I., García-Lidón, A., Guardiola, J.L., 1994.

$475 \quad$ Fruit splitting in 'Nova' hybrid mandarin in relation to the anatomy of the fruit and 476 fruit set treatments. Sci. Hortic. (Amsterdam). 57, 215-231.

477 Goldhamer, D.A., Fereres, E., 2001. Irrigation scheduling protocols using continuously 478 recorded trunk diameter measurements. Irrig. Sci. 20, 115-125.

479 Huang, X.-M., Wang, H.-C., Zhong, W.-L., Yuan, W.-Q., Lu, J.-M., Li, J.-G., 2008.

480 Spraying calcium is not an effective way to increase structural calcium in litchi 481 pericarp. Sci. Hortic. (Amsterdam). 117, 39-44. doi:10.1016/j.scienta.2008.03.007

Kasai, S., Hayama, H., Kashimura, Y., Kudo, S., Osanai, Y., 2008. Relationship 483 between fruit cracking and expression of the expansin gene MdEXPA3 in 'Fuji' apples (Malus domestica Borkh.). Sci. Hortic. (Amsterdam). 116, 194-198. doi:10.1016/j.scienta.2007.12.002

Kaufman, M.R., 1970. Extensibility of pericarp tissue in growing citrus fruit. Physiol. 487 Plant. 46, 778-781.

Kong, M., Lampinen, B., Shackel, K., Crisosto, C.H., 2013. Fruit skin side cracking and 489 ostiole-end splitting shorten postharvest life in fresh figs (Ficus carica L.), but are reduced by deficit irrigation. Postharvest Biol. Technol. 85, 154-161. doi:10.1016/j.postharvbio.2013.06.004

Morandi, B., Manfrini, L., Losciale, P., Zibordi, M., Corelli Grappadelli, L., 2010. Changes in vascular and transpiration flows affect the seasonal and daily growth of kiwifruit (Actinidia deliciosa) berry. Ann. Bot. 105, 913-23. doi:10.1093/aob/mcq070

Opara, L.U., Studman, C.J., Banks, N.H., 1997. Fruit skin splitting and cracking. Hortic. Rev. (Am. Soc. Hortic. Sci). 19, 217-262. doi:10.1007/s13398-014-0173- 
499 Peel, M.., Finlayson, B.L., McMahon, T.A., 2007. Updated world map of the Köppen-

$500 \quad$ Geiger climate classification. Hydrol. earth Syst. Sci. 11, 1633-1644.

$501 \quad$ doi:10.1127/0941-2948/2006/0130

502 Peet, M.., 1992. Fruit cracking in tomato. Horttechnology 2, 216-223.

503 Rabe, E., Van Rensburg, P.J.J., 1996. Gibberellic acid sprays, girdling, flower thinning 504 and potassium applications affect fruit splitting and yield in the 'Ellendale' tangor.

$505 \quad$ J. Hortic. Sci. 71, 195-203.

506 Rodríguez-Gamir, J., Intrigliolo, D.S., Primo-Millo, E., Forner-Giner, M.A., 2010.

507 Relationships between xylem anatomy, root hydraulic conductivity, leaf/root ratio

508 and transpiration in citrus trees on different rootstocks. Physiol. Plant. 139, 159-

$509 \quad$ 69. doi:10.1111/j.1399-3054.2010.01351.x

510 Sekse, L., 1995. Fruit cracking in sweet cherries (Prunus avium L.). Some physiological

511 aspects—a mini review. Sci. Hortic. (Amsterdam). 63, 135-141.

512 doi:10.1016/0304-4238(95)00806-5

513

514

515

516 


\section{Tables}

518 Table 1. Fruit splitting in citrus grown in Spain (Valencia, on the Mediterranean coast, and Huelva, on the Atlantic coast) and Uruguay (Libertad,

519 on the Rio de La Plata coast, and Salto, a continental plot). Data are means \pm standard error of 10 trees per orchard and year. Trees were budded

520 onto Carrizo citrange rootstock in Spain and Poncirus trifoliata rootstock in Uruguay.

521

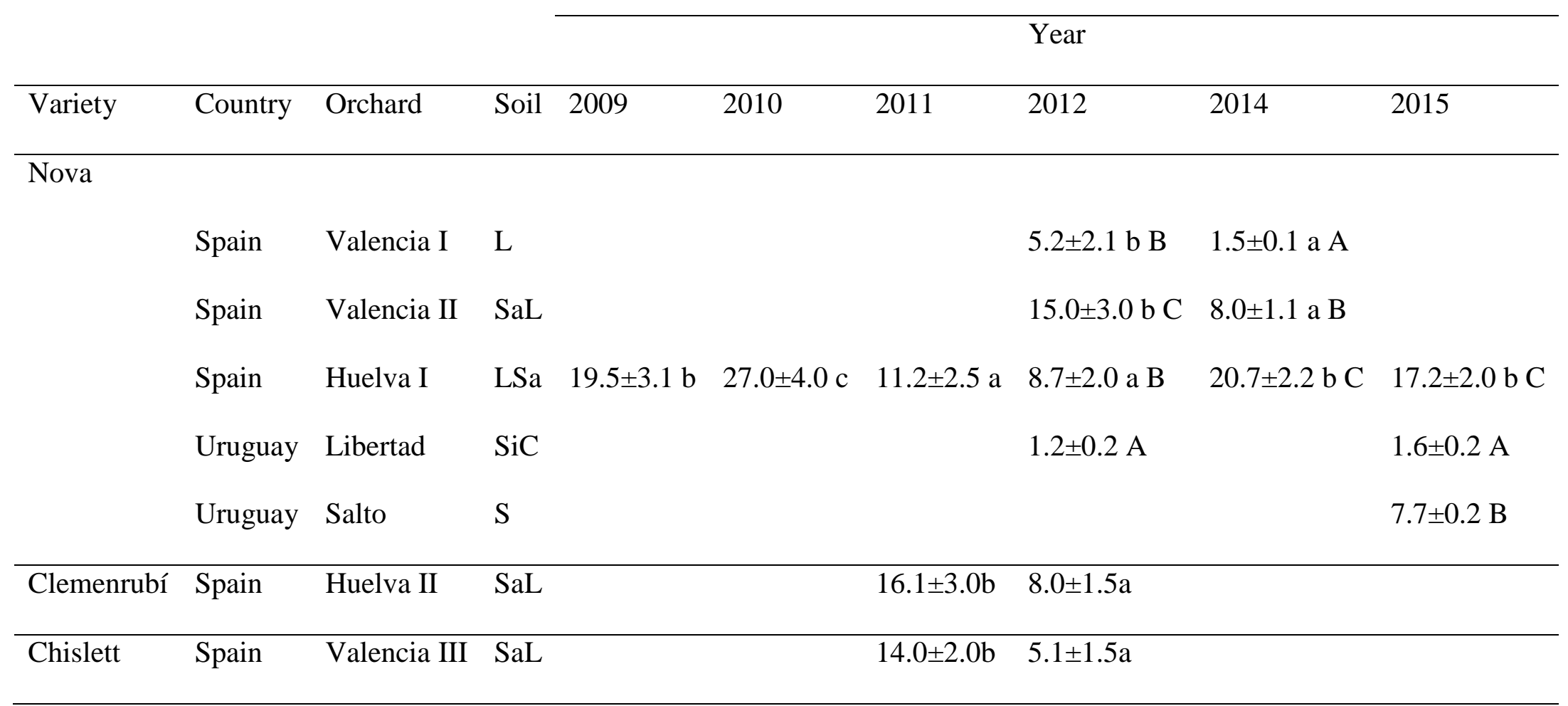


522 LSa: Loamy-sand; L: Loamy; SaL: Sandy-loam; SiC: Silty-clay-loam; S: Sand. Different minor and major case letters in the same row and 523 column, respectively, indicate significant differences $(\mathrm{P}<0.05)$. 


\section{Caption to figures}

525

526 Figure 1. Relationship between soil texture and percentages of split fruits per tree in the 527 Nova mandarin.

528

529 Figure 2. Relationship between fruit splitting and climatic conditions in the Nova 530 mandarin grown under loamy-sand soil (Huelva I orchard, 85\% sand), during the years 531 2010 (A, C, E, G, I) and 2012 (B, D, F, H, J). Data are means \pm standard error of 10 trees for splitting evaluation and 20 fruits per tree for diameter evaluation.

534 Figure 3. Time course of fruit splitting in the 'Nova' mandarin (A), precipitation (B) 535 and soil moisture (C) in two orchards with contrasting soil types in Uruguay (Salto, 536 fine-sand soil; Libertad, Silty-clay-loam soil). Data recorded in 2015.

538 Figure 4. Fruit growth rate (FGR) and trunk growth (TGR) rate patterns (in the same 539 tree) during the maximum splitting period (A, September $13^{\text {th }}$ to $19^{\text {th }} 2010$ ). Seasonal 540 pattern of fruit splitting and relative trunk growth rate (TGR) (B and D, 2010 and 2012, 541 respectively), and maximum daily shrinkage (MDS) (C and E, 2010 and 2012, 542 respectively). Data were recorded in the orchard Huelva I (Spain), which has loamy543 sand soil. Data are means \pm standard error of 10 trees for splitting evaluation.

545 Figure 5. The influence of rootstock on the incidence of fruit splitting and xylem vessel 546 area in 'Chislett' Navel orange, 'Nova' mandarin and 'Clemenrubí' Clementine 547 mandarin. Results are the average \pm of 10 trees per scion-rootstock combination (A) and 54810 cross-sections of average size peduncles from 10 fruits of each scion-rootstock 
549 combination (B). CL: Cleopatra mandarin; FA-5: Forner-Alcaide $\mathrm{n}^{\mathrm{o}}$ 5; C-35: C-35 550 citrange; CC: Carrizo citrange; PT: Poncirus trifoliata.

551

552 Figure 6. The influence of irrigation frequency on the percentage of split fruit and 553 canopy temperature in the Nova mandarin. Trees were irrigated daily (210 l tree ${ }^{-1}$ week $^{-}$ $5541,30 \mathrm{ltree}^{-1} \mathrm{~d}^{-1}$ ) or every other day (alternate irrigation, $200 \mathrm{l}$ tree $^{-1}$ week $^{-1}: 50 \mathrm{l}$ tree $^{-1} \mathrm{~d}^{-}$ $555{ }^{1}$ every other day). Data were recorded in Valencia (Spain). Data are means \pm standard 556 error of 10 trees for splitting evaluation. 